\title{
Price Priming Effects in Online Display Ads: An Abstract
}

\author{
Hamid Shaker, Sylvain Sénécal, Sihem Taboubi, and Yany Grégoire
}

\begin{abstract}
Although some studies (e.g., Drèze and Hussherr 2003; Yoo 2008) reveal that online ads can affect consumers even when they are trying to avoid them, there are no guidelines about communicating price information in online display ads as they are seen by consumers in a real online environment. Along with our interest in studying the effects of price anchor in online ads, we also study the effects of ad repetition. We focus on this attribute because ad repetition is one of the common strategies used to increase the effectiveness of the online advertisement (Malaviya et al. 1999; Yaveroglu and Donthu 2008). Again, to the best of our knowledge, the effects of ad repetition on price anchoring have not been studied in the context of incidental ad exposure in online environments.

Results of an eye-tracking study show that the magnitude of price stimuli can affect consumers' attention toward online display ads that consumers are exposed to incidentally. That is, consumers' fixation duration (pupil size) is longer (larger) for ads that contain high-value price stimuli than ads that contain low-value price stimuli. Moreover, when ads are displayed repeatedly on the same web page, the fixation duration is increased as a function of the order of placement only when ads contain high-value price stimuli. For ads containing low-value price stimuli, the gaze behavior did not change. We suggest that the observed different gaze behavior is due to a different price-processing mechanism for incidental price stimuli: When ads contain high-magnitude price stimuli, consumers process them through the elaborative selective accessibility mechanism (Strack and Mussweiler 1997); but when ads contain low-magnitude price stimuli, consumers process them through the more direct priming mechanism of anchoring and adjustment (Tversky and Kahneman 1974).
\end{abstract}

Keywords Online display ads · Price anchoring $\cdot$ Non-conscious price processing - Eye-tracking

Reference Available Upon Request

\footnotetext{
H. Shaker $(\bowtie) \cdot$ S. Sénécal $\cdot$ S. Taboubi · Y. Grégoire HEC Montréal, Montréal, Canada

e-mail: hamid.shaker@hec.ca; sylvain.senecal@hec.ca; sihem.taboubi@hec.ca; yany. gregoire@hec.ca
}

(C) The Academy of Marketing Science 2020

$\mathrm{S}$. Wu et al. (eds.), Marketing Opportunities and Challenges in a Changing Global Marketplace, Developments in Marketing Science: Proceedings of the Academy of Marketing Science, https://doi.org/10.1007/978-3-030-39165-2_215 